\title{
Diagnóstico de queilite actínica em paciente disfuncional: relato de caso
}

Diagnosis of actinic cheilitis in dysfunctional patient: case report

Diagnóstico de cheilitis actínica en pacientes disfuncionales: reporte de caso

Leticia Beatriz da Cruz SANTOS ${ }^{1}$

Ciro Augusto Souza DA SILVA ${ }^{2}$

Tiago Novaes PINHEIRO ${ }^{3}$

Antônio Jorge VASCONCELOS $\mathbf{I I}^{3}$

Lioney Nobre CABRAL ${ }^{3}$

${ }^{1}$ Graduanda em Odontologia, Escola Superior de Ciências da Saúde da Universidade do Estado do Amazonas - ESA/UEA 69.065-001 Manaus - AM, Brasil

${ }^{2}$ Aluno da Capacitação de Estomatologia e Patologia Bucal, Escola Superior de Ciências da Saúde da Universidade do Estado do Amazonas - ESA/UEA 69.065-001 Manaus - AM, Brasil

${ }^{3}$ Professor da Escola Superior de Ciências da Saúde da Universidade do Estado do Amazonas - ESA/UEA, 69.065-001 Manaus - AM, Brasil

\section{Resumo}

A queilite actínica (QA) é uma lesão comum do lábio inferior causada principalmente pela exposição com frequência elevada ou crônica à radiação solar. É considerada uma lesão cancerizável, onde o diagnóstico precoce pelo profissional é de extrema importância para o bom prognóstico do caso visto que a QA muitas vezes é a lesão precursora do carcinoma espinocelular de lábio inferior. $\mathrm{Na}$ área da saúde, é importante realizar um atendimento integral do paciente, criando uma interseção entre sua queixa principal e as necessidades que ele apresenta para que se consiga reestabelecer a saúde geral. O presente estudo visa apresentar um caso clínico de um paciente do gênero masculino, 38 anos de idade, que buscou o serviço odontológico para o tratamento de uma disfunção temporomandibular mas que, ao seu atendimento integralizado, percebeu-se a presença de uma lesão nodular em ventre lingual e de uma mácula leucoplásica em vermelhão de lábio inferior. Houve indicação para biópsia excisional da lesão nodular e de biópsia incisional para a lesão leucoplásica. Após o diagnóstico de neuroma traumático em língua e de queilite actínica em lábio inferior, com a confirmação histopatológica, foi realizada uma biópsia excisional simples. Após a remoção da lesão o paciente retornou para remoção de sutura e para proservação do caso, onde apresentou boa recuperação.

Descritores: Transtornos da Articulação Temporomandibular; Queilite; Diagnóstico Precoce.

\section{Abstract}

Actinic cheilitis (AC) is a common lesion of the lower lip caused mainly by exposure with high or chronic frequency to solar radiation. It is considered a cancerizable lesion, where the early diagnosis by the professional is extremely important for the good prognosis of the case since the AC is often the precursor lesion of the squamous cell carcinoma of the lower lip. In the health area, it is important to perform an integral care of the patient, creating an intersection between his main complaint and the needs he presents so that the general health can be reestablished. This study aims to present a clinical case of a male patient, 38 years old, who sought dental service for the treatment of a temporomandibular disorder but that to his care integralized was perceived the presence of a lesion Lingual belly and a leucoplastic macula in lower lip redness. There was indication for excisional biopsy of the nodular lesion and incisional biopsy for the leucoplastic lesion. After the diagnosis of traumatic neuroma in the tongue and actinic cheilitis in the lower lip, with histopathological confirmation, a simple excisional biopsy was performed. After removal of the lesion, the patient returned for suture removal and for proservation of the case, where he presented good recovery.

Descriptors: Temporomandibular Joint Disorders; Cheilitis; Early Diagnognosis.

\section{Resumen}

La queilitis actínica (QA) es una lesión común del labio inferior causada principalmente por la exposición con frecuencia alta o crónica a la radiación solar. Se considera una lesión cancerizable, donde el diagnóstico precoz por parte del profesional es extremadamente importante para el buen pronóstico del caso ya que la QA es a menudo la lesión precursora del carcinoma escamocelular del labio inferior. En el área de salud, es importante realizar un cuidado integral del paciente, creando una intersección entre su queja principal y las necesidades que presenta para que la salud general pueda ser reestablecida. Este trabajo tiene como objetivo presentar un caso clínico de un paciente varón, de 38 años de edad, que buscó el servicio dental para el tratamiento de un trastorno articulación temporomandibular, pero que para su cuidado integralizado se percibía la presencia de una lesión vientre lingual y una mácula leucoplástica en enrojecimiento del labio inferior. Se ha indicado la biopsia por escisión de la lesión nodular y la biopsia por incisión para la lesión leucoplástica. Después del diagnóstico de neuroma traumático en la lengua y la queilitis actínica en el labio inferior, con la Confirmación histopatológica, se realizó una simple biopsia por escisión. Después de la eliminación de la lesión, el paciente regresó para la extracción de sutura y para la proservación del caso, donde presentó una buena recuperación.

Descriptores: Trastornos de la Articulación Temporomandibular; Queilitis; Diagnostico Precoz.

INTRODUÇÃO

O câncer de cabeça e pescoço é uma das principais neoplasias que acomete a população mundial, com uma alta prevalência, sendo considerado um problema de saúde pública ${ }^{1}$. É uma neoplasia comum em homens de meia idade, tendo como fatores de risco o etilismo, tabagismo, infecções pelo HPV, higiene oral precária, alta exposição solar, dentre outros ${ }^{2}$.

Nas últimas décadas, o câncer ganhou uma dimensão maior, transformando-se em um problema de saúde pública mundial, tanto nos países desenvolvidos como naqueles em desenvolvimento. As estimativas para o Brasil no biênio 2018-2019 apontaram a ocorrência de 640 mil casos novos de câncer, para cada ano. Em relação ao câncer de boca, este é uma das dez malignidades mais frequentes, onde foram estimados 11.200 casos novos de câncer da cavidade oral em homens e 3.500 em mulheres para cada ano do biênio 2018-20193.

No Brasil, os registros hospitalares de câncer mostram que a boca representa a oitava localização mais frequente de tumores malignos, sendo o mais predominante da região de cabeça e pescoço, excluindo-se o de pele. 
As áreas mais afetadas da cavidade bucal são a língua, o assoalho de boca e o lábio inferior. A taxa de mortalidade por câncer de boca no Brasil está entre as mais altas do mundo ${ }^{4}$. Em 2013, 5.401 pacientes, sendo 4.223 homens e 1.178 mulheres, morreram em decorrência do câncer oral no Brasil ${ }^{3}$.

De acordo com o levantamento SEER do $\mathrm{NIH}$, cerca de $70 \%$ a $80 \%$ dos tumores na região de cabeça e pescoço são descobertos em fase avançada da doença, o que resulta em pior qualidade de vida, maiores taxas de morbimortalidade, maior risco de mutilação e maior complexidade no tratamento e na reabilitação do paciente ${ }^{5}$.

Mais do que um diagnóstico precoce, propiciar um tratamento precoce é fundamental para obtenção de um impacto efetivo na mortalidade e morbidade do câncer de boca ${ }^{6}$.

Tendo em vista a extrema importância do diagnóstico precoce para o tratamento e prognóstico do paciente, onde estima-se que 95\% dos casos registrados de carcinoma escamocelular (CEC) invasivo em região dos lábios seja originado da queilite actínica (QA), o presente estudo pretende relatar o caso de um paciente encaminhado para tratamento de disfunção temporomandibular e a potencial consequência parafuncional relacionada a condição, o neuroma traumático, onde o olhar atento profissional para a lesão labial mostrouse estratégico para a saúde do paciente.

CASO CLÍNICO

Paciente do sexo masculino, 38 anos de idade, melanoderma, operador de máquinas, com procedência do interior do Pará compareceu ao serviço da Policlínica Odontológica da UEA (POUEA) encaminhado do otorrinolaringologista com suspeita de disfunção temporomandibular, queixando-se de cefaleias e fortes dores e da região na nuca. Relatou ter sofrido há aproximadamente um ano um acidente de trabalho com dilaceração da periferia da asa do nariz do lado esquerdo estendida até o lábio superior, tendo quadros de cefaleia e de sensibilidade acentuada na nuca desde o ocorrido. Em 2017, paciente realizou exodontia dos incisivos centrais inferiores (Figuras 1 e 2), que estavam periodontalmente comprometidos, tendo diagnóstico de doença periodontal inflamatória crônica em fase avançada (Figuras 3 e 4). Durante a anamnese realizada no serviço da POUEA, relatou ainda possuir dores persistentes na região da nuca, com caráter intenso, continuo e espontâneo, sendo mais exacerbada pelo período da manhã. A dor irradiava para região mastoidea, ocasionando plenitude auricular no lado esquerdo e zumbido ipsilaterais.

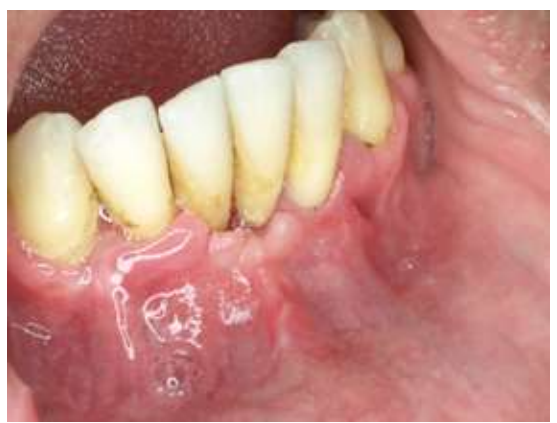

Figura 1: Imagem clínica inicial.

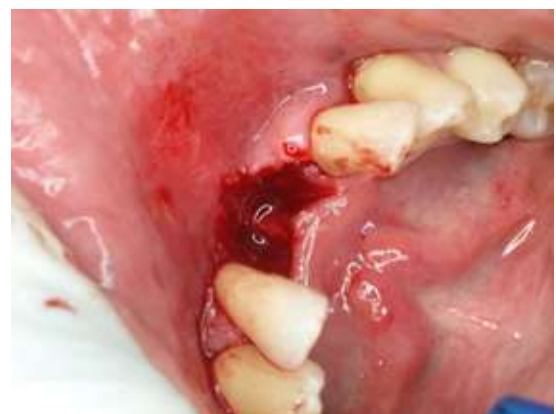

Figura 2: Imagem clínica após a exodontia dos elementos dentários 31 e 41.

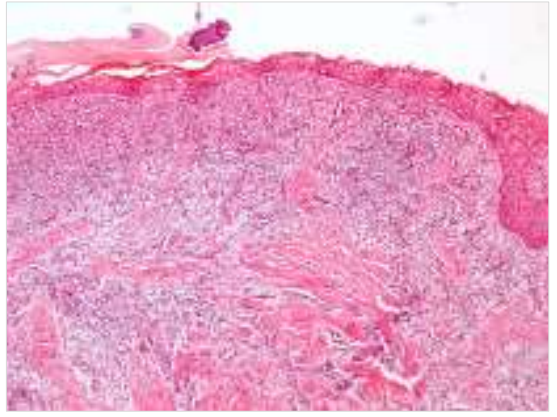

Figura 3: Fragmento de mucosa bucal revestido por epitélio estratificado pavimentoso paraqueratinizado hiperplásico em continuidade com o epitélio odontogênico crevicular estratificado pavimentoso desorganizado por extensa exocitose. Na superfície observam-se aglomerados microbianos planctônicos. Tecido conjuntivo subjacente apresentando intenso infiltrado inflamatório mononuclear predominantemente linfocitário.

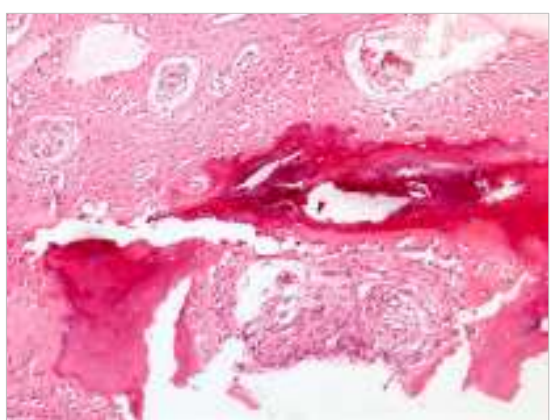

Figura 4: Tecido conjuntivo, não relacionado ao epitélio da mucosa e sulco periodontal, apresentando infiltrado inflamatório mononuclear. Presença de trabéculas ósseas viáveis em processo reabsortivo inflamatório.

Ao movimentar a mandíbula sentia leves estalidos e apresentava quadros esporádicos de vertigem. Ao exame clínico extraoral foi constatada a presença de pontos gatilhos em feixe anterior e médio do musculo temporal direito, em região profunda de masseter direito, 
porção mastoidea do musculo esternocleidomastóideo direito e no trigono suboccipital bilateral. Ao exame intraoral foi observado presença de uma lesão normocrômica, sólida e pediculada, medindo aproximadamente $4 \mathrm{~mm}$ localizada em ventre lingual, com hipótese diagnóstica de fibroma (Figura 5). Observou-se também uma lesão de superfície lisa, com presença mancha leucoplásica de formato irregular e limites nítidos em região do vermelhão do lábio inferior, com hipótese diagnostica de QA (Figura 6).

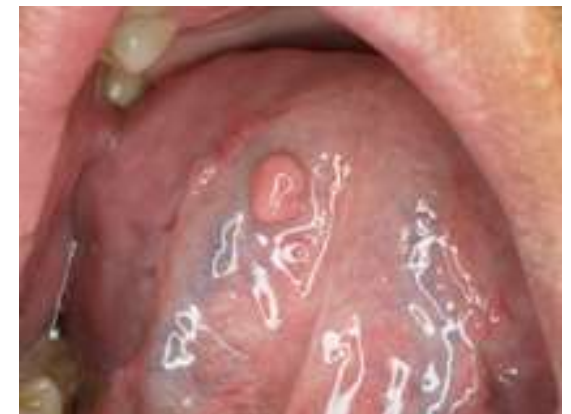

Figura 5: Lesão nodular normocrômica em região de ventre lingual.

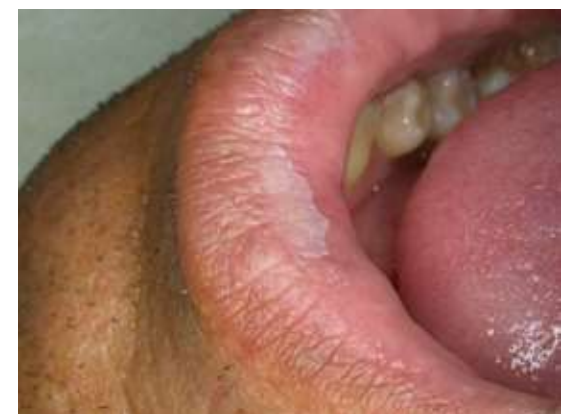

Figura 6: Lesão maculosa leucoplásica em região de vermelhão de lábio inferior.

Como conduta, optou-se pela confecção de uma placa miorrelaxante para tratamento da disfunção temporomandibular, associada a exercícios terapêuticos com fins de resolução dos quadros de cefaleia e dores na nuca, que representavam a queixa principal do paciente. Foi explanado ao paciente a presença das lesões observadas em ventre lingual vermelhão de lábio inferior, tendo como proposta a realização de biopsias excisional e biópsia incisional respectivamente regiões referidas (Figuras 7 e 8) e remoção de pontos após 7 dias.

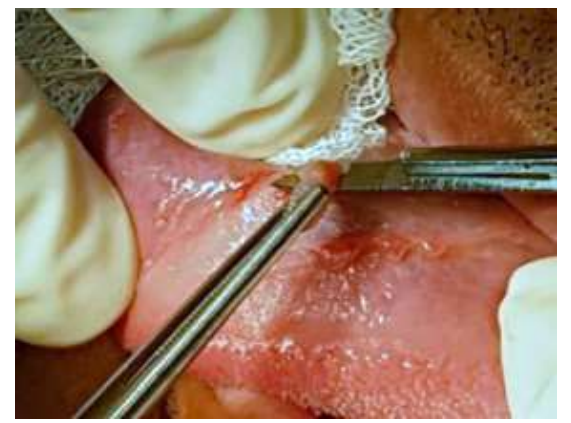

Figura 7: Biópsia excsional da lesão nodular localizada em ventre lingual.

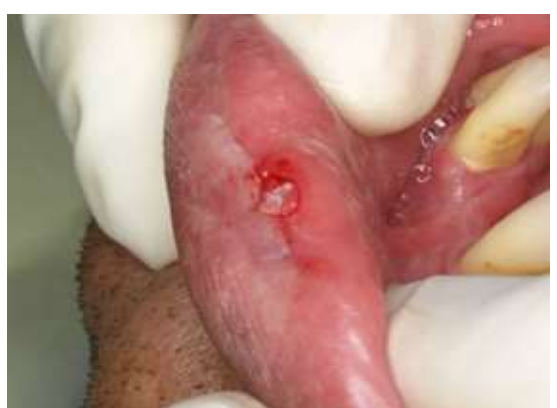

Figura 8: Biópsia incisional da lesão leucoplásica localizada em lábio inferior

$\mathrm{Na}$ análise histopatológica da biopsia excisional do nódulo em ventre lingual, foi observada mucosa bucal revestida por epitélio pavimentoso paraqueratinizado hiperplásico com subjacente tecido conjuntivo apresentando diversas áreas de feixes neurais desorganizados, com predomínio de células de Schwann frouxamente organizadas, associadas a capilares congestos e presença de tecido adiposo com aspecto de normalidade (Figura 9), sendo estabelecido o diagnóstico de neuroma, potencialmente originado no momento do trauma do acidente de trabalho ou pela atividade parafuncional associada a disfunção, que originou a queixa apresentada pelo paciente.

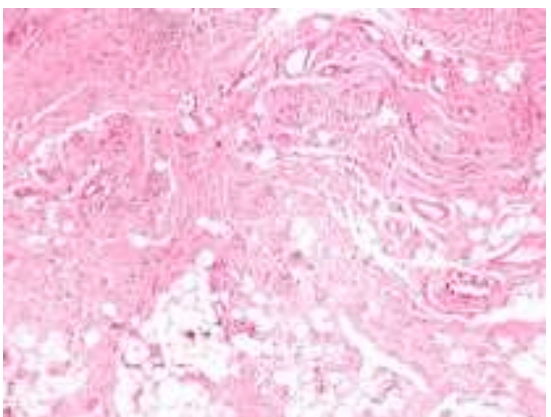

Figura 9: Predomínio de células de Schwann frouxamente organizadas, associadas a capilares congestos e presença de tecido adiposo com aspecto de normalidade.

$\mathrm{Na}$ análise histopatológica da biopsia incisional do lábio inferior revelou-se fragmento de semi-mucosa labial revestido por epitélio estratificado pavimentoso ortoqueratinizado hiperplásico com hipergranulose, acantose, aumento das camadas parabasais, com eventuais mitoses atípicas. Subjacente, o tecido conjuntivo frouxo não modelado apresentando alteração basofílica da matriz extracelular compatível com elastose solar, formando uma banda abaixo da região coriônica, além de discreto infiltrado inflamatório mononuclear subepitelial (Figuras 10). O corte histológico apresentou pleomorfismo, hipercromatismo e atipias celulares onde, após correlação clínica e histopatológica, foi elaborado o diagnóstico de QA com displasia de baixo grau, onde as margens da lesão estavam comprometidas perifericamente. Após correlação clínica e 
histopatológica, foi diagnosticado QA com displasia moderada em lábio inferior, optandose então por uma segunda abordagem cirúrgica (Figuras 11 a 15), visando a excisão total visto que a queilite se trata de uma lesão passível de malignização. O material biopsiado passou por nova análise histopatológica (Figura 15 e 16). Realizou-se a proservação do caso após 06 meses da realização das biópsias excisionais, sem o aparecimento de recidivas.

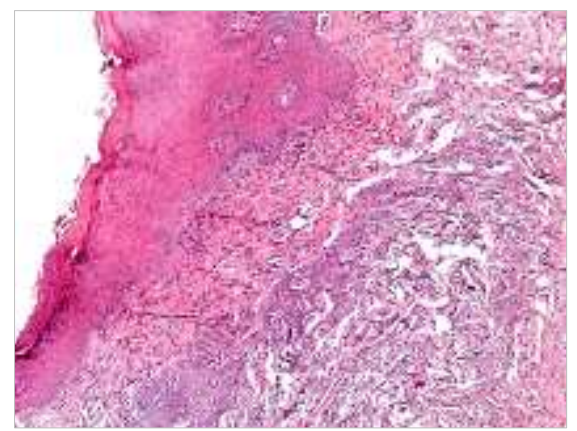

Figura 10: Epitélio estratificado pavimentoso ortoqueratinizado hiperplásico com hipergranulose, acantose, aumento das camadas parabasais, com eventuais mitoses atípicas.

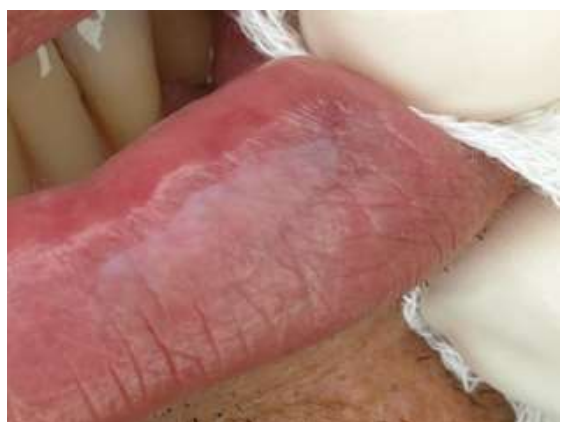

Figura 11: Imagem clínica da lesão leucoplásica maculosa em lábio inferior.

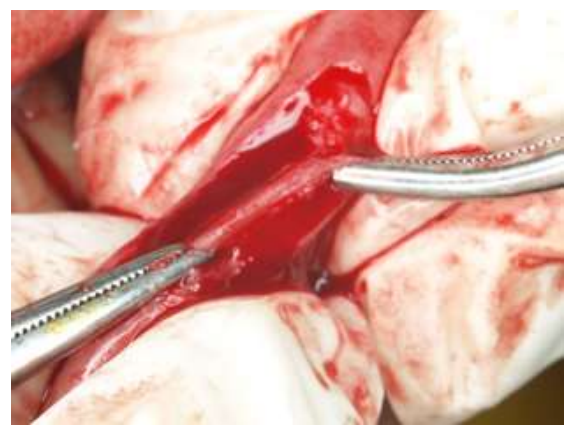

Figura 12: Pinçamento da artéria labial inferior para fins hemostáticos.

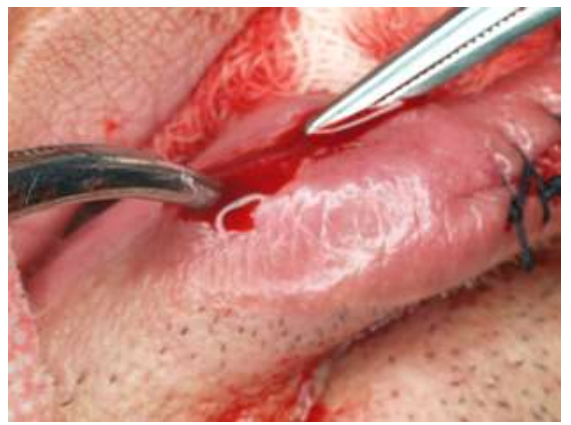

Figura 13: Pinçamento da artéria labial inferior para fins hemostáticos

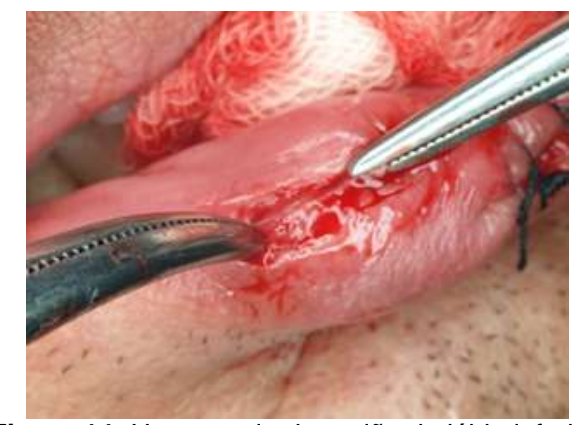

Figura 14: Hemostasia da região do lábio inferior.

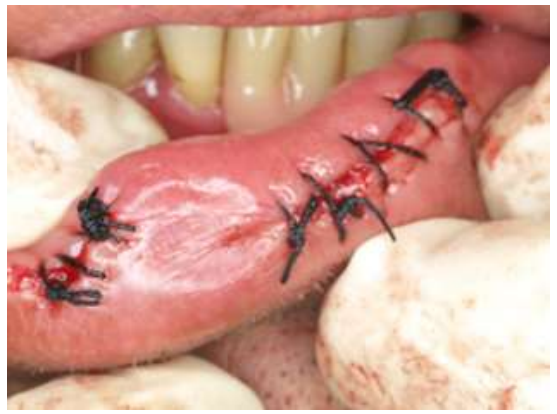

Figura 15: Sutura da área excisionada.

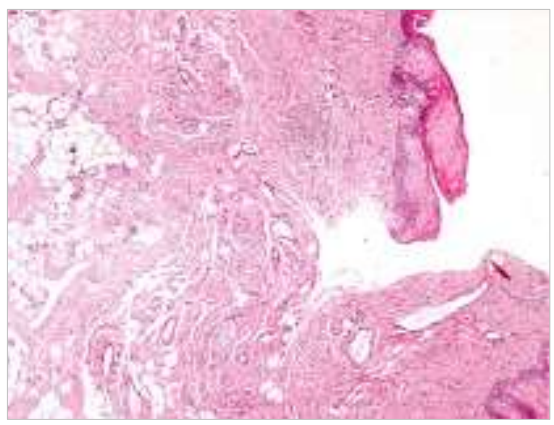

Figura 16: Tecido conjuntivo frouxo não modelado apresentando alteração basofílica da matriz extracelular compatível com elastose solar, com discreto infiltrado inflamatório mononuclear subepitelial.

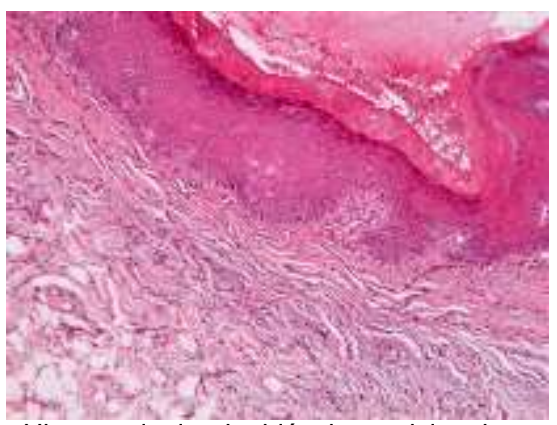

Figura 17: Histopatologia da biópsia excisional mostrando um epitélio estratificado pavimentoso hiperortoqueratinizado apresentando acantose, hipercromatismo parabasal, hipergranulose e numero aumentado de mitóticas típicas. Subjacente o tecido conjuntivo frouxo não modelado apresenta alteração basofílica de matriz compatível a elastose solar.

DISCUSSÃO

A queilite actínica (QA) é uma lesão comum do lábio inferior causada principalmente pela exposição com frequência elevada ou crônica à radiação solar ${ }^{7,8}$. Devido a associação com a radiação solar, é frequentemente mais reportada em países tropicais, onde observa-se que quanto maior a incidência de radiação ultravioleta (RUV) em regiões geográficas próximas a linha do equador, maiores os casos 
de doenças relacionadas com a exposição solar $^{9}$. Consequentemente, estados e regiões que estejam mais próximos da linha do equador tornam-se mais susceptíveis a lesões como a QA.

O Brasil recebe uma grande quantidade de raios ultravioletas, possuindo valores elevados em latitudes geográficas menores, em estações mais quentes, em horários específicos do dia e em diferentes condições meteorológicas. As regiões Norte e Nordeste apresentam maiores doses cumulativas de radiação ultravioleta em comparação com as regiões Sul e Sudeste em que o índice de RUV não sofre muita variação entre o inverno e o verão ${ }^{10}$. A proximidade da região Norte com a linha do equador e a latitude a qual os estados, como o Pará, se encontram contribui para maior quantidade de RUV e consequentemente um fator de risco para desenvolvimento da QA nessa região.

É considerada uma lesão cancerizável, sendo caracterizada clinicamente por áreas leucoplásicas de descoloração na mucosa labial ou no revestimento epitelial dos lábios, com graus variáveis de displasia ${ }^{11-14}$. A presença de superfície lisa com mancha leucoplásica de formato irregular em lábio inferior como achado clinico contribui para a hipótese diagnóstica da condição.

A lesão tem desenvolvimento insidioso, os pacientes com frequência não têm ciência dessa condição ${ }^{15}$. Geralmente, a QA é descoberta em fases avançadas ou mesmo quando o paciente busca tratamento para outras queixas, como no caso relatado.

A QA raramente acomete pessoas com idades abaixo de 45 anos, tendo forte predileção por pessoas de pele clara e pelo gênero masculino, com uma proporção homemmulher de cerca de 10:1 em alguns estudos ${ }^{15}$. No caso relatado, o paciente tem 38 anos, é melanoderma e é do gênero masculino, estando fora de alguns padrões epidemiológicos relatados na literatura.

Segundo a classificação da Organização Mundial de Saúde (OMS), a displasia epitelial pode ser classificada como leve, moderada ou grave, com base no grau de atipia citológica e arquitetura da camada epitelial perante análise histopatológica ${ }^{16}$. A meta análise publicada em 2009 demonstra que a taxa de transformação maligna de displasias orais é de aproximadamente $12 \%{ }^{17}$. A análise histopatológica no caso relatado confirmou 0 diagnóstico da QA, mostrando uma displasia de baixo grau, onde as margens da lesão apresentavam-se comprometidas perifericamente.
Cerca de 10 a $30 \%$ dos casos de QA podem sofrer transformação maligna para CEC, e, além disso, é estimado que $95 \%$ dos casos registrados desta malignidade em região dos lábios seja originado da condição, onde o diagnóstico precoce é de extrema importância para o tratamento e para o bom prognóstico do paciente ${ }^{18-20}$. Estudos mostram que clinicamente, a maioria das lesões podem ser diagnosticadas como QA (50,8\%), porém alguns destes casos reportados são histologicamente diagnosticados como CEC de lábio, enfatizando o valor diagnóstico da biopsia e da evolução histológica da lesão ${ }^{9}$. O diagnóstico do paciente com uma lesão ainda na sua fase incipiente foi o diferencial para o bom prognóstico do caso e para a saúde geral do paciente, até mesmo como forma preventiva para uma possível malignização, mediante a um olhar integralizado e não apenas da queixa que o trouxe ao serviço. Pacientes diagnosticados com CEC tem um tratamento com uma abordagem muito mais invasiva, com maior risco de mutilação e maior complexidade, enfatizando a importância de um diagnóstico incipiente em lesões que são passiveis de malignização.

O diagnóstico dessa condição envolve análise clínica e histopatológica ${ }^{21,22}$. De acordo com estudos, a QA é diagnosticada principalmente com base em achados clínicos, onde a biópsia só é necessária se a lesão tiver áreas erosivas endurecidas ou persistentes, sugerindo malignização ${ }^{23}$. Porém, a biópsia permite uma avaliação histológica adequada da peça e diagnóstico exato, sendo indicado a associação dos achados clínicos com a realização da biópsia ${ }^{24}$. Todos as outras opções de tratamento não produzem um espécime cirúrgico que permita análise anatomopatológica e consequente detecção de um possível tumor invasivo ${ }^{22}$. Além disso, a excisão total da lesão, além de contribuir para avaliação mais adequada e melhor diagnóstico, também atua como método terapêutico no tratamento da QA e na prevenção da piora prognostica do caso. Tendo como base estudos realizados, torna-se imprescindível para um diagnóstico mais preciso e seguro da condição a associação dos achados clínicos com o histopatológico.

A prevenção é a melhor forma de diminuir a incidência de $\mathrm{QA}$. $O$ diagnóstico precoce das lesões e intervenção em estágios precoces são as grandes e importantes chaves para a redução da mortalidade e morbidade. As lesões de QA que passam por longa e repetida exposição a fatores de risco, eventualmente progridem para $\mathrm{CEC}^{25}$. Pacientes com histórico de exposição crônica aos raios solares devem 
ser cuidadosamente acompanhados e, quando alterações labiais estão presentes, a biopsia da lesão e a evolução histopatológica devem der consideradas $^{9}$.

\section{CONSIDERAÇÕES FINAIS}

A visão integralizada do paciente tornase essencial para a captação de possíveis lesões, mesmo quando elas não são a queixa principal do paciente, assim como 0 acompanhamento e a proservação do caso tornam-se indispensáveis.

\section{REFERÊNCIAS}

1. Andrade J, Santos CA, Oliveira MP. Fatores associados ao câncer de boca: um estudo de caso-controle em uma população do Nordeste do Brasil. Rev bras epidemiol. 2015;18(4): 894-905.

2. Hashibe M, Brennan P, Chuang SC, Boccia S, Castellsague $\mathrm{X}$, Chen $\mathrm{C}$, et al. Interaction between tobacco and alcohol use and the risk of head and neck cancer: pooled analysis in the International Head and Neck Cancer Epidemiology Consortium. Cancer Epidemiol Biomarkers Prev. 2009;18(2):541-50.

3. Instituto Nacional do Câncer - INCA. Tipos de Câncer: Boca. [Citado em 2019 mar 29]. Disponível em: http://www2.inca.gov.br/wps /wcm/connect/ tiposdecancer/site/home/ boca

4. Salles JMP, Freire ARS, Vicenjte LCC, editores. Cancer de Boca: Uma visão multidisciplinar. Belo Horizonte: Coopmed; 2007

5. Howlader N, Noone AM, Krapcho M, Miller D, Bishop K, Kosary CL, et al. SEER Cancer Statistics Review, 1975-2014, National Cancer Institute. Bethesda, MD. Disponível em https://seer.cancer.gov/csr/1975_2014/

6. Ferlay J, Soerjomataram I, Ervik M, Dikshit R, Elser S, Mathers C, et al. GLOBOCAN 2012: Estimated Cancer Incidence, Mortality and Prevalence Worldwide in 2012. IARC Cancer Base.2012;1:11.

7. Gomes JO, Carvalho MV, Fonseca FP, Gondak RO, Lopes MA, Vargas PA. CD1a+ and CD83 + Langerhans cells are reduced in lower lip squamous cell carcinoma. J Oral Pathol Med. 2016;45(6):433-39.

8. Jadotte YT, Schwarts RA. Solar cheilosis: an ominious precursos partl. Diagnostic insights. J Am Acad Dermatol. 2012;66:173-84

9. Schalka S, Steiner D, Ravelli FN, et al. Brazilian consensus on photoprotection. An Bras Dermatol. 2014;89(6):1-74.

10. Mello FW, Melo G, Modolo F, Rivero ERC. Actinic cheillitis and lip squamoues cell carcinoma: Literature review and new data from Brazil. J Clin Exp Dent. 2019;11(1): 62-9

11. Markopoulos A, Albanidou-Farmaki E, Kayavis I. Actinic cheilitis: clinical and pathologic characteristics in 65 cases. Oral Dis.2004;10:212-16.

12. Warnakulasuriya $\mathrm{S}$, Johnson NW, van der Waal I. Nomenclature and classification of potentially malignant disorders of the oral mucosa.J Oral Pathol Med. 2007;36(10):575-80.

13. Cavalcante ASR, Anbinder AL, Carvalho YR. Actinic cheilitis: clinical and histological features. J Oral Maxillofac Surg. 2008;66(3): 498-503.

14. Cohen JL. Erbium laser resurfacting for actinic cheiliti. J Drugs Dermatol.2013;12(11):1290-92.

15. Neville BW, Damm DD, Allen CM, Bouquout JE. Oral and Maxillofacial Pathology, 3. ed. Philadelphia: Saunders; 2009.

16. El-Naggar AK, Chan J, Takata T, Grandis J, Blootweg P. WHO Classification of Tumors, Pathology and Genetic of Head and Neck Tumors, 4.ed. Lyon, France: IARC Press; 2017

17. Mehanna HM, Rattay T, Smith J, McConkey CC. Treatment and follow upo foral dysplasia a systematic review and meta-analysis. Head Neck. 2009.31(12):1600-9 .

18. Lopes ML, Silva Júnior FL, Lima KC, Oliveira PT, Silveira E. Clinicopathological profile and management of 161 cases of actinic cheilitis. An Bras Dermatol. 2015;90 (4):505-12

19. Savage NW, McKay C, Faulkner C. Actinic cheilitis in dental practice. Aust Dent. J. 2010; 55(Suppl 1):78-84

20. Murphy CT, Galloway TJ, Handorf A, Egleston BL, Wang LS, Mehra R et al. Survival impact of increasing time to treatment initiation for patients with head and neck cancer in the United States. J Clin Oncol. 2016. 34(2):169-78

21. Choi SH, Kim KH, Song KH. Efficacy of ablative fractionallaser-assisted photodynamic therapy for the treatment of actinic cheilitis: 12-month follow-up results of a prospective, randomized, comparative trial. $\mathrm{Br} \mathrm{J}$ Dermatol. 2015;173(1): 184-91.

22. Suárez-Pérez JA, López-Navarro N, HerreraAcosta E, Aguilera J, Gallego E, Bosch R et al. Treatment of actinic cheilitis with methyl aminolevulinate photodynamic therapy andlight fractionation: A prospective study of 10 patients. Eur J Dermatol. 2015;25(6):623-24.

23. Castiñeiras I, Del Pozo J, Mazaira $M$, Rodríguez-Lojo R, Fonseca E. Actinic cheilitis: Evolution to squamous cell carcinoma after carbon dioxide laser vaporization. A study of 43 cases. J Dermatol Treat. 2010;21(1):49-53

24. Satorres Nieto M, Gargallo Albiol J, Gay Escoda C. Surgical management of actinic cheilitis. Med Oral. 2001;6(3):205-17.

25. Vilella GM. Queilite Actinica - Revisão de literatura [monografia]. Belo Horizonte:UFMG; 2011. 


\section{CONFLITO DE INTERESSES}

Os autores declaram não haver conflitos de interesse

\section{AUTOR PARA CORRESPONDÊNCIA}

\section{Letícia Beatriz da Cruz Santos}

Rua Moacir Baima, Conjunto Nova Friburgo, 27 -

Parque 10 de Novembro

69.054-020 / Manaus - AM, Brasil

Telefone: (92) 99147-1663

E-mail: beatriz.leticia@live.com 